\title{
Effects of Olanzapine and Clozapine on Radial Maze Performance in Naive and MK-801-Treated Mice
}

Authors

Affiliation
O. Mutlu, I. K. Celikyurt, G. Ulak, P. Tanyeri, F. Y. Akar, F. Erden

Kocaeli University Medical Faculty, Pharmacology Department, Kocaeli, Turkey
Key words

atypical antipsychotics

- MK-801

- mice

radial arm maze task

- spatial memory received 15.09.2011

accepted 17.10.2011

\section{Bibliography}

DoI http://dx.doi.org/

10.1055/s-0031-1291360

Arzneimittelforschung 2012;

62: 4-8

(c) Georg Thieme Verlag KG

Stuttgart - New York

ISSN 0004-4172

\section{Correspondence}

O. Mutlu, MD

Department of Pharmacology

Faculty of Medicine

Kocaeli University

41380 Kocaeli

Turkey

Tel.: +90/262/3037250

Fax: +90/262/303 7003

oguzmutlu80@hotmail.com

\section{Abstract}

$\nabla$

Attention, working memory and long-term memory dysfunctions are the most commonly seen cognitive impairments in schizophrenic patients. Conflicting results exist regarding the effects of antipsychotics on cognitive abnormalities. The aim of this study was to investigate the effects of atypical antipsychotic drugs olanzapine $(0.4,0.8$ and $1.25 \mathrm{mg} / \mathrm{kg}$, i.p.) and clozapine (0.5 and $1 \mathrm{mg} / \mathrm{kg}$, i.p.) on spatial working memory in naive and MK-801 (0.2 mg/kg, i.p.) treated BALBc mice in an 8-arm radial arm maze (RAM) task.

\section{Introduction}

For many years, positive psychotic symptoms have been considered the hallmark of schizophrenia and have been the target of pharmacological treatment. During the last decade, it has become increasingly evident that schizophrenia is also associated with cognitive dysfunction [1]. Attention, working memory and long-term memory dysfunctions are the most commonly seen cognitive impairments in schizophrenic patients $[2,3]$. The treatment by using typical antipsychotics has been reported to be ineffective $[4,5]$ or even impairing cognitive functions [6]. Atypical antipsychotics, for example, olanzapine [7] and sertindole [8], have been shown to improve negative symptoms without inducing extrapyramidal syndrome.

One of the mechanisms responsible for cognitive impairments in schizophrenia is the hypofunction of N-methyl-D-aspartate (NMDA) receptors [9]. NMDA receptor antagonists such as ketamine and phencyclidine induce schizophrenia-like symptoms in healthy subjects, including positive, negative, and cognitive symptoms [9]. MK-801 is an NMDA receptor antagonist that is widely used in animal models of psychosis and induces a variety of cognitive disturbances related to schizo-
None of the antipsychotic drugs studied altered number of errors in naive mice, whereas MK-801 significantly increased working memory errors in RAM test. Olanzapine and clozapine potently reversed MK-801 induced increasement of working memory errors. Olanzapine and clozapine prolonged latency of the animals in naive mice. The MK-801-induced enhancement in the speed of mice in performing the RAM task was blocked by olanzapine but not clozapine. Our study shows that atypical antipsychotics olanzapine and clozapine might improve cognitive deficits in schizophrenic patients.

phrenia. It impairs learning and memory functions that depend on the hippocampus and the amygdala [10].

Atypical antipsychotics have been established to be more effective in improving memory dysfunctions than conventional antipsychotics [11]. Effects of atypical antipsychotics on the cognitive function reported in the literature are inconsistent $[4,5,12,13]$ although the results could be dependent on the type of the measured cognitive function [14].

Because the cognitively beneficial effects of a treatment may have a high impact on the patients' quality of life, the main area of investigation is research related to the efficacy of a new antipsychotic therapy in diminishing cognitive impairments. Thus, we aimed to investigate the effects of the atypical antipsychotic drugs olanzapine and clozapine on spatial working memory in naive mice as well as on MK-801-induced cognitive dysfunction in a radial arm maze (RAM) test in mice.

\section{Materials and Methods \\ $\nabla$}

Animals

190 male inbred BALB/c ByJ mice (MAM TUBITAK, Gebze, Kocaeli-Turkey), aged 7 weeks at their 
arrival to the laboratory, were used in this study. They were kept in the laboratory for 2 weeks before the onset of the experiments. Mice were housed $4-5$ per cage at $21 \pm 1.5^{\circ} \mathrm{C}$ under a $12 \mathrm{~h}$ light/dark cycle (light onset at 8.00 p.m.). Tap water and food pellets were available ad libitum. All procedures for the treatment of animals were in compliance with the European Community Council Directive of 24 November 1986, and ethical approval was granted by the Kocaeli University Ethics Committee (Number: AEK 1/2, Kocaeli, Turkey). All animals used were naive to the experimental apparatus. The experiments were conducted between 9:00a.m. and 12:00 p.m. in a semi-soundproof and semi-dark laboratory. Different mice were used in each experiment.

\section{Radial arm maze (RAM)}

The experimental device was an elevated maze with 8 open arms (32-cm long and 5-cm wide) leading to an $8-\mathrm{cm}$ square platform, which radiated from a central circular platform $44 \mathrm{~cm}$ in diameter with $1-\mathrm{cm}$ high sides surrounding each arm. A small cup, $1 \mathrm{~cm}$ in diameter, was embedded in each distal platform, and it contained a hidden $10 \mathrm{mg}$ noodle used as reinforcement. The maze was oriented in a small room, on the walls of which 4 large black, white or black and white striped patterns hung, which provided particularly salient visual extramaze cues. For further details on the apparatus, see Beuzen et al. [15]. 24h prior to training, the mice were deprived of food but not water; their weight loss reached $15-20 \%$ of the initial body weight by the start of testing.

Radial arm maze procedure was applied according to Belzung et al. 2000 [16]. Mice were first given 2 pretraining sessions at 24-h intervals. Groups of 4 mice were placed on the maze at the same time and for $20 \mathrm{~min}$ per session, and could freely explore the 8 arms, which contained abundant food. Following pretraining, mice were given 5 training sessions, at 90-min intervals.

After baiting the 8 arms with a $10 \mathrm{mg}$ noodle, a mouse was placed on the central platform. Sessions were terminated when the animal had visited all 8 arms and eaten the rewards, after 16 arms were visited (regardless of which arms), or after a maximum of $15 \mathrm{~min}$. The maze was quickly cleaned with ethanol to remove fecal deposits and urine after each mouse had completed testing. An error was recorded when the mouse entered an arm previously visited during the retention session. The total number of errors and the latency of retention session (time taken to complete the task) were scored. Since the effects of drugs on locomotor activity of the animals may cause false results, the speed of the animals was recorded using ethovision-XT (Noldus, Netherlands).

\section{Drugs}

MK-801 (CAS 77086-22-7) was purchased from Sigma (St. Louis, USA). Olanzapine (CAS 132539-06-1) was supplied as a gift by the Biofarma drug company (Istanbul, Turkey), clozapine (CAS 578621-0) was a gift from the Adeka drug company (Samsun, Turkey). Olanzapine and clozapine were dissolved in saline with the addition of a few drops of $0.1 \mathrm{M}$ hydrochloric acid, and MK-801 was dissolved in saline. All drugs were freshly prepared and administered in a volume of $0.1 \mathrm{~mL}$ per $10 \mathrm{~g}$ body weight. Control groups received the same volume of vehicle. Olanzapine $(0.4,0.8$ and $1.25 \mathrm{mg} / \mathrm{kg}$, i.p.), clozapine (0.5 and $1 \mathrm{mg} / \mathrm{kg}$, i.p.) and MK-801 $(0.2 \mathrm{mg} / \mathrm{kg}$, i.p.) were administered 60,30 and $30 \mathrm{~min}$ before the fifth session (retention session) in the radial arm maze test, respectively. The number of animals per group ranged from 6-10. Doses of drugs were selected according to behavioral and neurochemical studies demonstrating the intended effect of the drugs $[4,17,18]$.

\section{Statistics}

The number of working memory errors, latency and the speed of the animals in the radial arm maze test were analyzed by using 2-way analysis of variance (ANOVA) followed by Dunnett's post hoc test. Data are expressed as the means \pm SEM. The level of significance was defined as $\mathrm{p}<0.05$.

\section{Results}

$\nabla$

Naive mice were trained during 4 trials and olanzapine $(0.4,0.8$ and $1.25 \mathrm{mg} / \mathrm{kg}$, i.p.), clozapine (0.5 and $1 \mathrm{mg} / \mathrm{kg}$, i.p.) and MK-801 (0.2 mg/kg, i.p.) was administered 60, 30 and $30 \mathrm{~min}$ respectively, before the beginning of fifth trial. No sedation was applied to the MK-801 treated animals; none of the animals included in the experiment died.

\section{Effects of olanzapine on spatial memory in the radial arm maze test}

In the evaluation of the effects of acute treatment with olanzapine $(0.4,0.8$ and $1.25 \mathrm{mg} / \mathrm{kg})$, given $60 \mathrm{~min}$ before the retention trial, on the number of errors in naive or MK-801-treated mice in the RAM test, a significant difference between the groups was observed (2-way ANOVA post hoc Dunnett's test; $F(7,66)=6.78$; $p<p<0.001)$. Olanzapine $(0.4,0.8$ and $1.25 \mathrm{mg} / \mathrm{kg})$ given alone had no effect on the number of errors, whereas MK-801 (0.2 mg/ $\mathrm{kg}$ ) significantly increased the number of working memory errors in the RAM test in mice $(p<0.01)$. Olanzapine at all doses significantly decreased the number of working memory errors in MK-801-treated mice ( $p<0.05, p<0.01, p<0.01$, respectively) in the RAM test ( $\bullet$ Fig. 1a).

When the effect of olanzapine on the latency (time taken to complete the task) of the animals in naive and MK-801-treated mice in the RAM test was evaluated, there was a significant difference between the groups (2-way ANOVA post hoc Dunnett's test; $F(7,66)=3.72 ; p<0.01)$. Olanzapine significantly increased the latency of the animals at 0.8 and $1.25 \mathrm{mg} / \mathrm{kg}$ doses $(p<0.05$ and $p<0.01$, respectively), whereas MK-801 slightly but insignificantly increased this parameter $(p>0.05)$. Olanzapine at $1.25 \mathrm{mg} / \mathrm{kg}$ doses, but not at other doses, significantly increased the latency of MK-801-treated mice $(p<0.05)$ ( $\bullet$ Fig. 1b).

The speed of mice in performing the RAM task (which reflects the locomotor activity of the animals) after acute injection of the drugs in the retention trial of the RAM test was significantly different between the groups (2-way ANOVA post hoc Dunnett's test; $F(7,66)=8.60 ; p<0.001)$. Olanzapine $(1.25 \mathrm{mg} / \mathrm{kg})$ significantly decreased the speed of the animals $(p<0.05)$, whereas MK-801 treatment significantly enhanced this parameter $(p<0.01)$. MK-801-induced enhancement in the speed of animals was reversed by olanzapine at all of the doses used $(0.4,0.8$ and $1.25 \mathrm{mg} / \mathrm{kg} ; p<0.01, p<0.05$ and $p<0.05$, respectively) in the RAM test ( $\bullet$ Fig. 1c).

\section{Effects of clozapine on spatial memory in the radial} arm maze test

The effect of acute injection of clozapine ( 0.5 and $1 \mathrm{mg} / \mathrm{kg}$ ), administered $30 \mathrm{~min}$ before the retention trial, on the number of errors in naive and MK-801-injected mice in the RAM test was significantly different between the groups (2-way ANOVA post hoc Dunnett's test; $F(5,34)=12.52 ; p<0.001)$. Clozapine $(0.5$ and $1 \mathrm{mg} / \mathrm{kg}$ ) showed no effect on the number of errors, whereas MK-801 (0.2 mg/kg) significantly increased the number of errors 


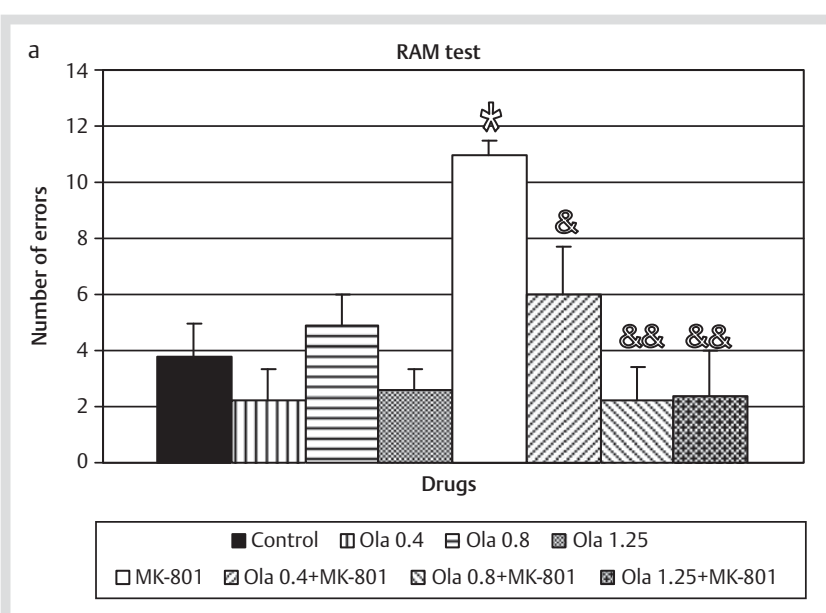

Fig. 1a Effects of olanzapine on working memory errors in the RAM test. Olanzapine $(0.4,0.8$, or $1.25 \mathrm{mg} / \mathrm{kg}$, i.p., $\mathrm{n}=9-10)$ or vehicle $(\mathrm{n}=10)$ was administered $60 \mathrm{~min}$ before the retention trial. MK-801 $(0.2 \mathrm{mg} / \mathrm{kg}$, i.p., $\mathrm{n}=10$ ) was administered $30 \mathrm{~min}$ before the test. ${ }^{*} p<0.05$ vs. control group, $\& p<0.05, \& \& p<0.01$ vs. MK- 801 group.

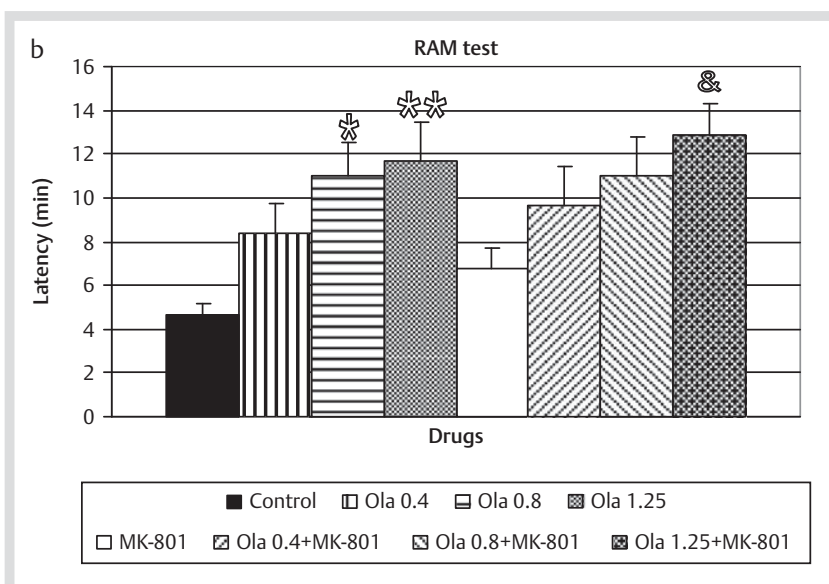

Fig. 1b Effects of olanzapine on latency per arm entry in the RAM test. Olanzapine $(0.4,0.8$, or $1.25 \mathrm{mg} / \mathrm{kg}$, i.p., $n=9-10)$ or vehicle $(n=10)$ was administered $60 \mathrm{~min}$ before the test. MK-801 $(0.2 \mathrm{mg} / \mathrm{kg}$, i.p., $\mathrm{n}=10)$ was administered $30 \mathrm{~min}$ before the test. ${ }^{*} p<0.05,{ }^{* *} p<0.01$ vs. control group, $\& p<0.05$ vs. MK-801 group.

in the RAM test in mice $(p<0.01)$. The MK-801-induced increase in the number of errors was reversed by clozapine $(0.5$ and $1 \mathrm{mg} /$ $\mathrm{kg})(p<0.05)$ in the RAM test ( $\bullet$ Fig. $2 \mathbf{2 a}$ ).

There was a significant difference between the groups when evaluating the effects of clozapine on the latency (time taken to complete the task) of naive and MK-801-treated mice in the RAM test (2-way ANOVA post hoc Dunnett's test; $F(5,34)=5.83$; $P=0.001)$. Clozapine significantly prolonged the latency of the animals at $1 \mathrm{mg} / \mathrm{kg}$ doses $(p<0.01)$, whereas MK-801 had no effect ( $\bullet$ Fig. 2b).

The speed of mice in performing the RAM task was significantly different between the groups (2-way ANOVA post hoc Dunnett's test; $F(5,34)=8.31 ; p<0.001)$. Clozapine failed to affect the speed of the animals, whereas MK-801 significantly increased this parameter $(p<0.01)$. Moreover, clozapine failed to reverse the MK-801-induced increase in the speed of animals in the RAM test ( $\bullet$ Fig. 2c).

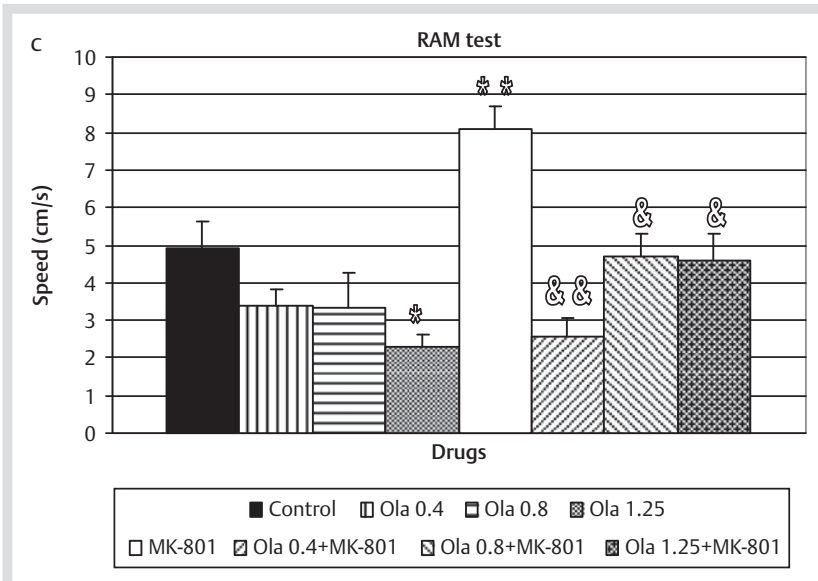

Fig. 1c Effects of olanzapine on speed of mice in the RAM test. Olanzapine $(0.4,0.8$, or $1.25 \mathrm{mg} / \mathrm{kg}$, i.p., $\mathrm{n}=9-10)$, or vehicle $(n=10)$ was administered $60 \mathrm{~min}$ before the test. MK-801 $(0.2 \mathrm{mg} / \mathrm{kg}$, i.p., $\mathrm{n}=10)$ was administered $30 \mathrm{~min}$ before the test. ${ }^{*} p<0.05,{ }^{* *} p<0.01$ vs. control group, $\& p<0.05, \& \& p<0.01$ vs. MK-801 group.

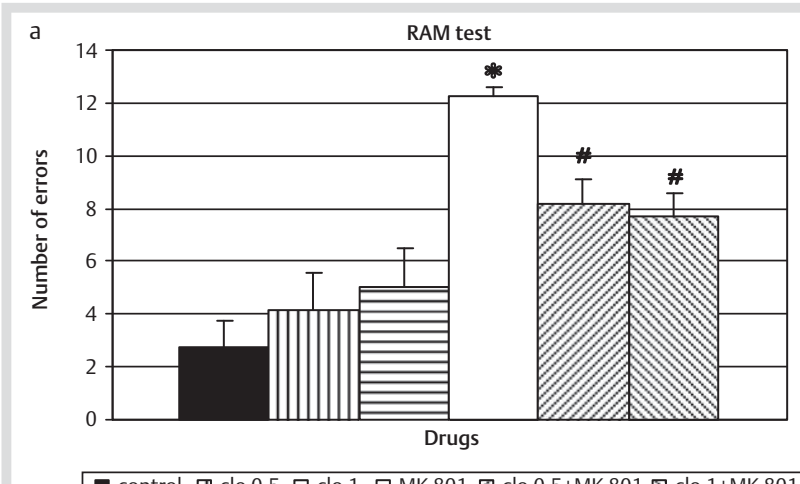

Fig. 2a Effects of clozapine on working memory errors in the RAM test. Clozapine ( 0.5 and $1 \mathrm{mg} / \mathrm{kg}$, i.p., $\mathrm{n}=6$ ) or vehicle $(\mathrm{n}=8)$ was administered $30 \mathrm{~min}$ before the retention trial. MK- $801(0.2 \mathrm{mg} / \mathrm{kg}$, i.p., $\mathrm{n}=8)$ was administered $30 \mathrm{~min}$ before the test. ${ }^{*} p<0.01$ vs. control group, $\# p<0.05$ vs. MK-801 group.

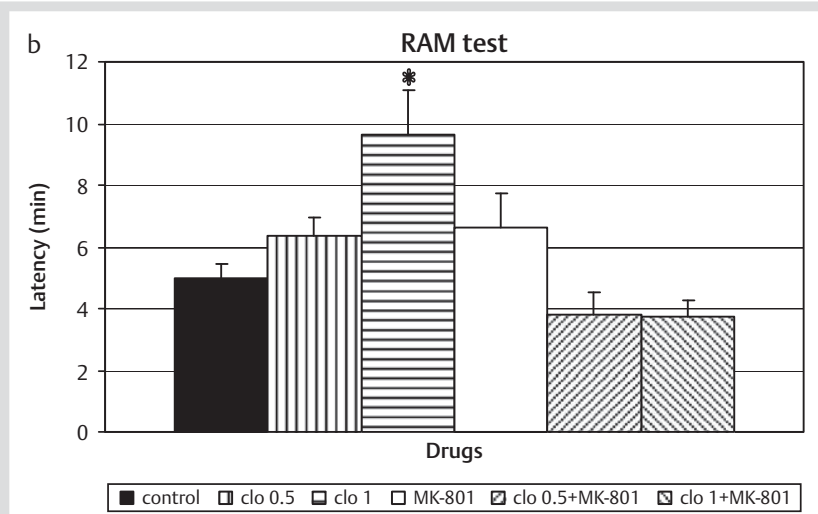

Fig. 2b Effects of clozapine on latency per arm entry in the RAM test. Clozapine $(0.5$ and $\mathrm{mg} / \mathrm{kg}$, i.p., $\mathrm{n}=6)$ or vehicle $(\mathrm{n}=8)$ was administered $30 \mathrm{~min}$ before the test. MK- $801(0.2 \mathrm{mg} / \mathrm{kg}$, i.p., $\mathrm{n}=8)$ was administered $30 \mathrm{~min}$ before the test). ${ }^{*} p<0.01$ vs. control group. 


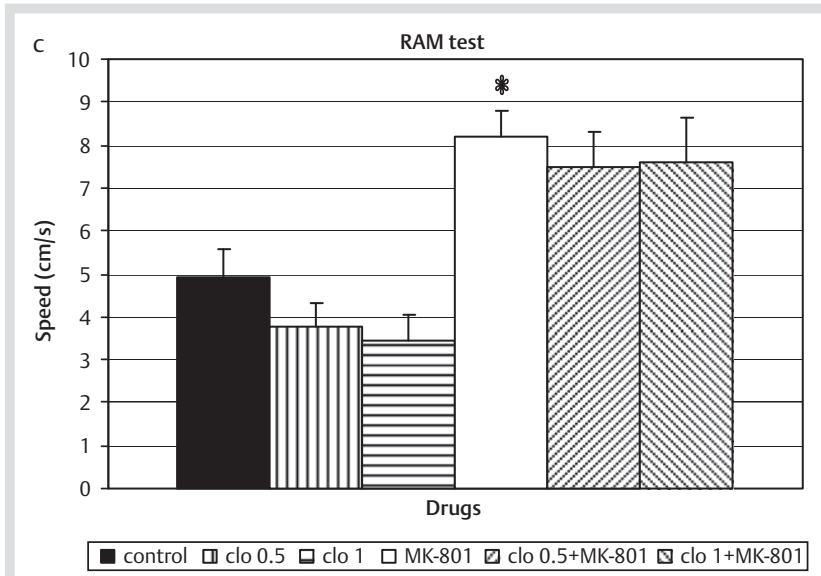

Fig. 2c Effects of clozapine on speed of mice in RAM test. Clozapine (0.5 and $1 \mathrm{mg} / \mathrm{kg}$, i.p., $\mathrm{n}=6)$ or vehicle $(\mathrm{n}=8)$ was administered $30 \mathrm{~min}$ before the test. MK- $801(0.2 \mathrm{mg} / \mathrm{kg}$, i.p., $\mathrm{n}=8)$ was administered $30 \mathrm{~min}$ before the test. ${ }^{*} p<0.01$ vs. control group.

\section{Discussion}

$\nabla$

This study reveals that the second-generation atypical antipsychotic drugs olanzapine and clozapine both have beneficial effects on MK-801-induced memory impairment in the RAM test, although clozapine and olanzapine can exert side effects on locomotion in naive mice.

It has been shown that, in the RAM test, the ability to make a series of correct choices depends on spatial information from extramaze cues [19-21]. In our protocol, the effect of drugs on spatial memory is evaluated, because performance in the maze requires sufficient memory of the spatial environment. Each of the arms is baited with food, and the reentry to a previously visited arm is accepted as an error; thus, spatial working memory is thougt to be examined.

Conflicting results have been obtained for the effects of antipsychotics on learning and memory. In one study, clozapine failed to improve verbal working memory in patients with schizophrenia [22], although in another study, the drug reversed subchronic phencyclidine-induced impairment in spatial working memory in rats [23]. In a working memory test, a delayed response task in rats, low doses of haloperidol, clozapine and risperidone induced a delay-independent impairment, but sertindole treatment failed to exert an effect [24]. In a recent study, a novel atypical antipsychotic lurasidone reversed MK-801-induced impairment of learning and memory in both the MWM test and the RAM test [25].

Clozapine and olanzapine have affinities for numerous neurotransmitter receptors, such as dopaminergic, serotonergic, muscarinic, $H_{1}$, and $\alpha_{1^{-}}, \alpha_{2^{-}}$, and $\beta$-adrenergic receptors [26-28]. The most notable pharmacological difference between olanzapine and chlorpromazine (i.e., the feature that is thought to confer atypicality) is olanzapine's high affinity (as an antagonist) for $5 \mathrm{HT}_{2 \mathrm{~A}}$ receptors [29]. $5 \mathrm{HT}_{2 \mathrm{~A}}$ antagonists have been associated with improvements in information processing, attention, and working memory in rodents and in non-human primates [30,31]. The positive effects of atypical antipsychotic drugs might be due to the ability of these drugs to enhance dopamine and acetylcholine efflux [13].

Olanzapine causes a dose-related increase in the extracellular concentration of dopamine in the rat prefrontal cortex [32], which may contribute to improved cognitive functioning. Olanzapine's high affinity and antagonistic activity at the 5- $\mathrm{HT}_{6}$ receptor [33] may also be important for its ability to improve memory. Pre-clinical evidence has suggested that $5-\mathrm{HT}_{6}$ antagonists may improve cognitive function [34], possibly due to the selective enhancement of excitatory neurotransmission [35]. Clozapine and olanzapine may also influence cognitive performance due to antihistaminergic effects [29]. A strong correlation between increased histamine $\mathrm{H}_{1}$ occupancy and decreased locomotion and cognitive performance was shown in human studies $[36,37]$. The diminishing effect of olanzapine at $1.25 \mathrm{mg} / \mathrm{kg}$ on speed and prolonging effect of olanzapine and clozapine on latency of the animals at higher doses in naive animals in this study can be related to their histaminergic antagonistic effects. Both olanzapine and clozapine did not alter the number of errors compared to control group therefore we can not conclude the deterioration of memory by olanzapine and clozapine in naive mice.

The ability of atypical antipsychotics to block $5-\mathrm{HT}_{2 \mathrm{~A}}$ receptors within the prefrontal cortex may also lead to an increase in dopamine transmission and diminish some aspects of cognitive dysfunction associated with dopamine loss. A high $5 \mathrm{HT}_{2 \mathrm{~A}}$ dopamine $D_{2}$ receptor affinity ratio seems to be related to successful treatment of the negative symptoms of schizophrenia [38], and this effect improves cognitive dysfunctions.

Animals treated with NMDA receptor antagonists, such as PCP, ketamine, or MK801, are used to model various aspects of schizophrenia. These animals show symptoms including hyperlocomotion, enhanced stereotypic behaviors, cognitive and sensorimotor gating deficits, and impaired social interactions [39]. Hyperactivity and many other behavioral abnormalities produced by noncompetitive NMDA receptor antagonists are blocked by most of the typical and atypical antipsychotics $[40,41]$. Clozapine, olanzapine and sertindole have antagonistic effects on $5-\mathrm{HT}_{2 \mathrm{~A}}, 5-\mathrm{HT}_{2 \mathrm{C}}$, and $\alpha_{1}$-adrenergic receptors, with higher potencies than the effects on dopamine $D_{2}$ receptors. It is known that selective ligands of these receptors (e.g., M100907 (5-HT $2 \mathrm{~A})$ and prazosin $\left(\alpha_{1}\right)$, respectively) can inhibit locomotor hyperactivity induced by MK-801 $[42,43]$. Antipsychotics with potent $5-\mathrm{HT}_{2 \mathrm{~A}}$ and $\alpha_{1}$-adrenergic antagonistic activity also block MK-801-induced hyperactivity [42], which was also demonstrated in the present study. Olanzapine reversed the MK-801induced hyperactivity while clozapine had no effect in doses used in our study. It can be expected to observe the same effects by higher doses of clozapine in further studies.

As a conclusion, the second-generation antipsychotics olanzapine and clozapine seem to exert a beneficial effect on MK-801 induced cognitive dysfunction following acute treatment at the doses used similar to our previous studies $[44,45]$ in mice. Further research, including the assessment of neuronal and molecular factors and comparing effects of atypicals antipsychotics with a classical one, is needed to clarify the effects of atypical antipsychotics in various learning tasks on different forms of memory, and such approaches may facilitate the development of better antipsychotics for the treatment of cognitive deficits associated with schizophrenia.

\section{Acknowledgements}

\section{$\nabla$}

We would like to thank Biofarma and Adeka Pharmaceuticals for supplying olanzapine and clozapine. 


\section{Conflict of Interest}

$\nabla$

Authors report no biomedical financial interests or potential conflicts of interests.

\section{References}

1 Green MF, Kern RS, Braff DL et al. Neurocognitive deficits and functional outcome in schizophrenia: are we measuring the "right stuff"? Schizophr Bull 2000; 26: 119-136

2 Green MF, Nuechterlein KH, Gold JM et al. Approaching a consensus cognitive battery for clinical trials in schizophrenia: the NIMH-MATRICS conference to select cognitive domains and test criteria. Biol Psychiatry 2004; 56: 301-307

3 Harvey PD, Green MF, Keefe RS et al. Cognitive functioning in schizophrenia: a consensus statement on its role in the definition and evaluation of effective treatments for the illness. J Clin Psychiatry 2004; 65: 361-372

4 Didriksen M, Skarsfeldt T, Arnt J. Reversal of PCP-induced learning and memory deficits in the Morris' water maze by sertindole and other antipsychotics. Psychopharmacology 2007; 193: 225-233

5 Mortimer AM. Cognitive function in schizophrenia - do neuroleptics make a difference? Pharmacol Biochem Behav 1997; 56: 789-795

6 Cleghorn JM, Kaplan RD, Szechtman B et al. Neuroleptic drug effects on cognitive function in schizophrenia. Schizophr Res 1990; 3: 211-219

7 Fulton B, Goa KL. Olanzapine, a review of its pharmacological properties and therapeutic efficacy in the management of schizophrenia and related psychoses. Drugs 1997; 53: 281-298

8 Kane JM, Tamminga CA. Sertindole (serdolect): preclinical and clinical findings of a new atypical antipsychotic. Exp Opin Invest Drugs 1997; 6: 1729-1741

9 Krystal JH, Karper LP, Seibyl JP et al. Subanesthetic effects of the noncompetitive NMDA antagonist, ketamine, in humans. Psychotomimetic, perceptual, cognitive, and neuroendocrine responses. Arch Gen Psychiatry 1994; 51: 199-214

10 Jafari-Sabet $M$. NMDA receptor antagonists antagonize the facilitatory effects of post-training intra-basolateral amygdala NMDA and physostigmine on passive avoidance learning. Eur J Pharmacol 2006; 529: $122-128$

11 Harvey PD, Kefe RS. Studies of cognitive change in patients with schizophrenia following novel antipsychotic treatment. Am J Psychiatry 2001; 158: 176-184

12 Goldberg TE, Greenberg RD, Griffin SJ et al. The effect of clozapine on cognition and psychiatric symptoms in patients with schizophrenia. Br J Psychiatry 1993; 162: 43-48

13 Meltzer HY, McGurk SR. The effects of clozapine, risperidone, and olanzapine on cognitive function in schizophrenia. Schizophr Bull 1999; 25: 233-255

14 Hoff AL, Faustman WO, Wieneke $M$ et al. The effect of clozapine on symptom reduction, neurocognitive function, and clinical management in treatment-refractory state hospital schizophrenic inpatients. Neuropsychopharmacology 1996; 15: 361-369

15 Beuzen A, Belzung $C$, Roullet $P$. Drug effects in a radial maze designed for dissociation of cues used by mice. Pharmacol Biochem Behav 1994; 48: 23-29

16 Belzung C, Le Guisquet AM, Griebel G. b-CCT, a selective BZ-v receptor antagonist, blocks the anti-anxiety but not the amnesic action of chlordiazepoxide in mice. Behav Pharmacol 2000; 11: 125-131

17 Didriksen M, Kreilgaard M, Arnt J. Sertindole, in contrast to clozapine and olanzapine, does not disrupt water maze performance after acute or chronic treatment. Eur J Pharmacol 2006; 542: 108-115

18 Skarsfeldt $T$. Differential effect of antipsychotics on place navigation of rats in the Morris water maze. Psychopharmacology 1996; 124: 126-133

19 Nagai T, Kamei H, Dohniwa M et al. Involvement of hippocampal extracellular signal-regulated kinase $1 / 2$ in spatial working memory in rats. Neuroreport 2006; 17: 1453-1457

20 Suzuki S, Augerinos G, Black AH. Stimulus control of spatial behavior on the eight-arm maze in rats. Learn Motiv 1980; 11: 1-18

21 Zou LB, Yamada K, Nabeshima T. Sigma receptor ligands (+)- SKF10,047 and SA4503 improve dizocilpine-induced spatial memory deficits in rats. Eur J Pharmacol 1998; 355: 1-10

22 Lee MA, Jayathilake K, Meltzer HY. A comparison of effect of clozapine with typical neuroleptics on cognitive function in neurolepticresponsive schizophrenia. Schizoph Res 1999; 37: 1-12
23 Jentsch JD, Tran A, Le D et al. Sub-chronic phencyclidine administration reduces mesoprefrontal dopamine utilization and impairs prefrontal cortical-dependent cognition in the rat. Neuropsychopharmacology 1997; 17: 92-99

24 Didriksen $M$. Effects of antipsychotics on cognitive behaviour in rats using the delayed non-match to position paradigm. Eur J Pharmacol 1995; 281: 241-250

25 Enomoto T, Ishibashi T, Tokuda $\mathrm{K}$ et al. Lurasidone reverses MK-801induced impairment of learning and memory in the Morris water maze and radial-arm maze tests in rats. Behav Brain Res 2008; 186: 197-207

26 Bymaster F, Perry KW, Nelson DL et al. Olanzapine: a basic science update. Br J Psychiatry Suppl 1999; 37: 36-40

$27 \mathrm{He} \mathrm{H,} \mathrm{Richardson} \mathrm{JS.} \mathrm{A} \mathrm{pharmacological,} \mathrm{pharmacokinetic} \mathrm{and} \mathrm{clinical}$ overview of risperidone, a new antipsychotic that blocks serotonin 5-HT2 and dopamine D2 receptors. Int Clin Psychopharmacol 1995; 10: $19-30$

28 Stephenson CM, Pilowsky LS. Psychological of olanzapine. A review. Br J Psychiatry 1999; 38: 52-58

29 Schotte A, Janssen PF, Gommeren W et al. Risperidone compared with new and reference antipsychotic drugs: in vitro and in vivo receptor binding. Psychopharmacology 1996; 124: 57-73

30 Terry AV Jr, Buccafusco JJ, Bartoszyk GD. Selective serotonin 5-HT2A receptor antagonist EMD 281014 improves delayed matching performance in young and aged rhesus monkeys. Psychopharmacology (Berl) 2005; 179: 725-732

31 Winstanley CA, Chudasama Y, Dalley JW et al. Intra-prefrontal 8-OHDPAT and M100907 improve visuospatial attention and decrease impulsivity on the five-choice serial reaction time task in rats. Psychopharmacology (Berl) 2003; 167: 304-314

$32 \mathrm{Li}$ XM, Perry KW, Wong DT et al. Olanzapine increases in vivo dopamine and norepinephrine release in rat prefrontal cortex, nucleus accumbens and striatum. Psychopharmacology 1998; 136: 153-161

33 Bymaster FP, Falcone JF, Bauzon D et al. Potent antagonism of 5-HT(3) and 5-HT(6) receptors by olanzapine. Eur J Pharmacol 2001; 430: 341-349

34 Rogers DC, Robinson TL, Quilter CA et al. Cognitive enhancement effects of the selective 5-HT6 antagonist SB-271046. Br J Pharmacol 1999; 127: 22

35 Dawson LA, Huy O, Nguyen BS et al. The 5-HT6 receptor antagonist SB271046 selectively enhances excitatory neurotransmission in the rat frontal cortex and hippocampus. Neuropsychopharmacology 2001; 25: 662-668

36 Okamura $N$, Yanai K, Higuchi $M$ et al. Functional neuroimaging of cognition impaired by a classical antihistamine, D-chlorpheniramine. $\mathrm{Br}$ J Pharmacol 2000; 129: 115-123

37 Tashiro M, Mochizuki H, Iwabuchi K et al. Roles of histamine in regulation of arousal and cognition: functional neuroimaging of histamine H1 receptors in human brain. Life Sci 2002; 72: 409-414

38 Altar CA, Wasley AM, Neale RF et al. Typical and atypical antipsychotic occupancy of D2 and S2 receptors: an autoradiographic analysis in rat brain. Brain Res Bull 1986; 16: 517-525

39 Lipska BK, Weinberger DR. To model a psychiatric disorder in animals: schizophrenia as a reality test. Neuropsychopharmacology 2000; 23: 223-239

40 Abdul-Monim Z, Reynolds GP, Neill JC. The atypical antipsychotic ziprasidone, but not haloperidol, improves phencyclidine-induced cognitive deficits in a reversal learning task in the rat. J Psychopharmacol 2003; 17: 57-65

41 Cartmell J, Monn JA, Schoepp DD. Attenuation of specific PCP-evoked behaviors by the potent mGlu2/3 receptor agonist, LY379268 and comparison with the atypical antipsychotic, clozapine. Psychopharmacology (Berl) 2000; 148: 423-429

42 Gleason SD, Shannon HE. Blockade of phencyclidine-induced hyperlocomotion by olanzapine, clozapine and serotonin receptor subtype selective antagonists in mice. Psychopharmacology 1997; 129: 79-84

43 Mathé JM, Nomikos GG, Hildebrand BE et al. Prazosin inhibits MK801-induced hyperlocomotion and dopamine release in the nucleus accumbens. Eur J Pharmacol 1996; 309: 1-11

44 Mutlu O, Ulak G, Celikyurt IK et al. Effects of olanzapine, sertindole and clozapine on learning and memory in the Morris water maze test in naive and MK-801-treated mice. Pharmacol Biochem Behavior 2011; 98: 398-404

45 Mutlu O, Ulak G, Celikyurt IK et al. Effects of olanzapine, sertindole and clozapine on MK-801 induced visual memory deficits in mice. Pharmacol Biochem Behavior 2011; 99: 557-565 